\title{
La Malinche sob a visão de José Limón
}

Dóris Giacomolli

Recebido em: 7 de outubro de 2019

Aceito em: 18 de outubro de 2019
Escritora, autora de dois romances: "O que querem os deuses" e "Com a alma entre os dentes." Doutora em Letras pela FURG, graduada e mestre em Letras pela UFPEL, professora de língua inglesa e literatura. Contato: dorishsss@smail.com ou sitewww.dorisgiacomolli.com.br. Brasil 
PALAVRAS-CHAVE:

Malinche; José Limón;

chicanas; feminismo; literatura; colonização mexicana.

KEYWORDS: Malinche; José Limón; chicanas; feminism; Mexican colonization.
Resumo: Nesse artigo pretendo abordar, a partir da obra José Limón and La Malinche: The dancer and the Dance de Patricia Seed, o espetáculo de La Malinche, de autoria de José Limón, coreógrafo mexicano. Esse livro, que contém artigos de vários acadêmicos voltados para cenário, figurinos, música, notas coreográficas e conteúdo histórico sobre a peça musical, nos permitirá conhecer aspectos da construção de sua protasonista indísena: a Malinche que esteve ao lado de Hernán Cortés durante a captura do México e que, desde então, se destaca em trabalhos historiográficos, acadêmicos e literários, não só no México, mas em diversas partes do mundo.

Abstract: In this article I intend to approach, from the work José Limón and La Malinche: The dancer and the Seed Dance of Patricia, the show of La Malinche, authored by José Limón, Mexican choreographer. This book, which contains articles by various academics focused on scenery, costumes, music, choreographic notes and historical content about a musical piece, will allow us to learn about the construction of its indigenous protagonist: Malinche, who was with Hernán Cortés during the capture of the Mexico and, since then, stands out in historiographic, academic and literary works, not only in Mexico, but in different parts of the world. 


\section{INTRODUÇÃO}

José Limón escolheu uma enigmática figura feminina, a Malinche, para tema e personagem central de um espetáculo musical. A Malinche foi uma mulher de uma família nahúalt, amante e intérprete de Cortés, que se configura como uma das personagens mais controversas desde as fontes primárias da história e que ocupa papel de destaque na historiografia, trabalhos acadêmicos e literários.

$\mathrm{Na}$ introdução ao livro José Limón and La Malinche: the dancer and the dance, a editora Patrícia Seed apresenta José Limón:

José Acadio Limón (1908-1972) alcançou fama em uma nova forma de arte do século XX. Aprendiz de Charles Weidman e Doris Humphrey, duas grandes figuras da segunda geração do movimento de dança moderna, Limón assumiu seu lugar como o único americano-mexicano entre um círculo de elite de dançarinos modernos do século XX - um campo cujos fundadores eram principalmente mulheres e incluíam Isadora Duncan, Martha Graham e Mary Wigman, bem como as talentosas africana-americana coreógrafas Pearl Primus e Katherine Dunham. (Seed, 2008, 1, tradução nossa). ${ }^{1}$

Segundo Seed $(2008,1)$ José Acadio Limón nasceu no México, em uma família de classe média. Por dificuldades financeiras a família mudou-se para Los Angeles em 1923 e a vida não foi fácil, como não era para aqueles que iam para os Estados Unidos para fazerem parte do exército de mexicanos

1 José Acadio Limón (1908-1972) attained renown in a new twentieth century art form. Apprenticed to Charles Weidman and Doris Humphrey, two major figures in the second generation of the modern dance movement, Limón assumed his place as the lone Mexican American among an elite circle of twentieth-century modern dancer - a field whose founders were mainly female and included Isadora Duncan, Martha Graham, and Mary Wigman as well as the talented African American choreographers Pearl Primus and Katherine Dunham. (Seed, 2008, 1). 
que não dominavam a língua inglesa. Devemos destacar também que aos mexicanos-americanos foram conferidos sentimentos antifraude, devido ao número decrescente de empregos durante a depressão de 1929. Apesar disso, Limón cursou um semestre de universidade, mas abandonou os estudos e dirigiu-se para o caminho artístico. Ao assistir um espetáculo de dança, descobriu o que queria fazer. Assim, começou a dançar nos palcos e, em 1946, fundou sua companhia de dança e tornou-se o diretor artístico.

Durante as décadas de 1950 e 1960, como um dos grandes artistas mexicanoamericano do século viajou para mais de uma dúzia de países da Europa à América Latina como embaixador cultural dos Estados Unidos. Ele treinou uma geração de estudantes na famosa Juilliard School de Nova York em sua técnica, recebeu duas das mais altas honras em seu campo e criou peças teatrais que ainda hoje continuam sendo amplamente realizadas. No entanto, apesar de todas essas conquistas, fora de uma comunidade fortemente unida de artistas, poucas pessoas conhecem seu nome. (Seed, 2008,1 , tradução nossa). ${ }^{2}$

De acordo com Seed (2008, 4), Limón coreografou sete temas mexicanos em seus espetáculos. O que aqui nos interessa é o de La Malinche:

Em La Malinche, Limón revisitou a história da Conquista do México e sua mais famosa participante feminina e ícone cultural em uma forma de dança unicamente vívida. Apresentado primeiramente nos Estados Unidos, depois no México e, posteriormente, na Rússia, Canadá, Europa Ocidental e Oriente Médio, La Malinche permaneceu por décadas entre as apresentações mais

2 During the 1950s and 1960s, one of the great Mexican American artists of the century traveled to more than a dozen countries in Europe and Latin America as a cultural ambassador of the United States. He trained a generation of students at New York's famed Juilliard School in his technique, received two of the highest honors in his field, and created theatrical pieces that even today remain widely performed. Yet despite all these achievements, outside of a tightly knit community of artists few people know his name. (Seed, 2008, 1). 
populares da empresa no exterior. Embora sua recepção crítica nesses países permaneça oculta nos arquivos de jornais de todo o mundo, os membros da empresa lembram a recepção entusiasmada dada à dança. Tendo circulado táo amplamente em todo o mundo, a representação de La Malinche por Limón merece consideração como uma interpretação artisticamente importante de um assunto mexicano concebido e traduzido nos Estados Unidos. (Seed, 2008, 5-6, traduçáo nossa). ${ }^{3}$

A autora, além de considerar a importância de Limón, destaca a relevância da figura histórica da Malinche e dá suas razôes para deter-se nesse tema: essa mulher real equivale, no México, à poeta Sor Juana Inês da Cruz do século XVII e à Virgem de Guadalupe.

A estudiosa assim compreende a aproximação entre os termos Malinche e Virgem de Guadalupe:

Um foco inicial dos estudos feministas foi a reavaliação dos arquétipos femininos nacionais, incluindo a Virgem de Guadalupe e a Malinche. Inicialmente, a Malinche foi evitada na visão feminista mexicana; mulheres menos complicadas ofereciam exemplos de ativismo social feminino. Do outro lado da fronteira, no entanto, chicanas se apropriaram do simbolismo de Malinche e investiram em recontar sua história. (Jager, 2015, 202, tradução nossa). ${ }^{4}$

3 In La Malinche Limón revisited the history of Mexico's Conquest and its most famous female participant and cultural icon in a uniquely vivid dance form. Presented first in the United States, then in Mexico, and subsequently in Russia, Canada, Western Europe, and the Middle East, La Malinche remained for decades among the company's most popular presentations overseas. Though its critical reception in those countries remains buried in newspaper archives around the world, members of the company recall the enthusiastic reception given the dance. Having circulated so widely around the globe, Limon's representation of La Malinche merits consideration as an artistically important interpretation of a Mexican subject conceived and rendered in the United States. (Seed, 2008, 5-6).

4 An early focus of feminist scholarship was the reevaluation of national feminine archetypes, including the Virgin of Guadalupe and La Malinche. Initially, Malinche was avoided in Mexican feminist scholarship; less complicated women offered examples of female social activism. Across the border, 
Malinche é um potente ícone cultural feminino compartilhado entre as fronteiras e culturas mexicana e mexicana-americana. Mulheres de ascendência mexicana, chicanas do México e Estados Unidos, reivindicaram Malinche como símbolo para suas lutas. Höller $(2010,5)$ detalha o significado do termo chicana, explicando que essa palavra, bem como o adjetivo pátrio composto "mexicano-americano", se refere a pessoas de ascendência mexicana. Esses vocábulos são empregados por muitos escritores de forma intercambiável. Entretanto, o uso pode diferir consideravelmente em termos de perspectivas políticas. No texto de Jager, o termo chicana é usado para referir a pessoas de ascendência mexicana. Já de acordo com Höller $(2010,12)$ esse termo refere-se, basicamente, ao sentimento de pertencer a duas fronteiras.

Como figura histórica, Malinche esteve sempre presente durante todos os encontros de Cortés com Montezuma ${ }^{5}$ e outros indígenas importantes, bem como espionou seus contemporâneos e conterrâneos a favor de Hernán Cortés, para com quem teve uma lealdade inabalável. Ela parece ter preferido, como homem, o estrangeiro que veio de longe, que cruzou o oceano para destruir o lugar a que ela pertencia.

O mais peculiar é que Malinche não desapareceu após quinhentos anos. Ainda que sua história tenha sido enfraquecida e quase apagada das narrativas espanholas, continuou a aparecer em pinturas coloniais de artistas

however, Chicanas appropriated Malinche's symbolism and invested themselves in retelling her history. (Jager, 2015, 202).

5 Montezuma detinha o título de Huey Tlatoani, o Grande Orador, líder dos astecas, quando Hernán Cortés chegou ao Novo Mundo. 
nahúalt e mexicanos, além de nos códices indígenas da época, e encantou romancistas e acadêmicos, retornando com força total no final do século XVIII. De acordo com Seed $(2008,6)$, nos anos que antecederam a independência da Espanha em 1821, intelectuais mexicanos, como parte de um esforço maior para se distinguir de seus senhores espanhóis, tornaram-se cada vez mais interessados em temas indígenas. Assim, de acordo com várias visôes, a Malinche ressurgiu: o jesuíta colonial e historiador Francisco Javier Clavijero a transformou em uma heroína romântica. A tendência romântica na literatura no México estendeu-se até o final do século XIX e representaçóes abrangentes carregaram esse ícone. $\mathrm{O}$ historiador americano William Prescott escreveu Conquest of Mexico $(1843)^{6}$ e alcançou sucesso ao mostrar a Malinche como uma grande dama elegante, chegando inclusive a mencionar que ela teria se reconciliado com sua família após a Conquista.

Durante a segunda década do século XX surgiu uma nova visão política para a nação; e alguns autores e romances adquiriram uma tendência miscigenadora entre espanhóis e indígenas, tornando-os parceiros, amigos, iguais. $\mathrm{O}$ indígena é celebrado e o espanhol não é execrado, mas responsabilizado por fazer algo importante para o México, ao ter tornado o país católico.

Nem todos os autores do começo do século XXI viram o surgimento da mestiçagem com bons olhos e preferiram encarar o resultado do relacionamento entre Hernán Cortés e Malinche como indesejado. Assim esse passou a ser interpretado como advindo não de um relacionamento amoroso, mas

6 Prescott, William H. Historia de la Conquista de México. Traducción de Rafael Torres Pabón. Madrid: Antonio Machado, 2004. 
em decorrência de uma relação senhor-escrava, impossível de evitar, sem direito à escolha ou livre-arbítrio, fato que derivou na representação de um mestiço triste e inconformado consigo mesmo. Essa inconformidade no modo de encarar a mestiçagem perpetuou-se até a metade do século XX, dividindo-se entre a visão amorosa e a visão coercitiva da relação sexual entre Cortés e Malinche.

Em 1947 Octávio Paz escreve o artigo El laberinto de La soledad no qual encara o relacionamento entre Cortés e Malinche como uma forma de estupro: o espanhol que estupra a nativa sendo que a prole derivada de tal relacionamento não poderia ser saudável e feliz; por isso, o resultado era um ser acabrunhado e escondido dentro de si mesmo. No capítulo Os filhos de Malinche, Paz (1947) escreve:

Se a Chingada é uma representação da Mãe violada, não me parece forçado associá-la à Conquista, que também foi uma violação, não apenas no sentido histórico, mas também na carne dos índios. O símbolo da entrega é a senhora Malinche, a amante de Cortés. É verdade que ela se entrega voluntariamente ao conquistador, mas este, táo logo ela deixa de lhe ser útil, a esquece. Dona Marina se tornou uma figura que representa a índia, fascinada, estuprada ou seduzida pelos espanhóis. E, do mesmo modo que o menino náo perdoa a mãe para deixá-lo e ir em busca de seu pai, o povo mexicano não perdoa a traição de Malinche. Ela encarna o aberto, o maldito, na frente de nossos índios, estoicos, impassíveis e fechados. Cuauhtémoc e Doña Marina são, portanto, dois símbolos antagônicos e complementares. (Paz, 1947, 35, tradução nossa). ${ }^{7}$

7 Si la Chingada es una representación de la Madre violada, no me parece forzado asociarla a la Conquista, que fue también una violación, no solamente en el sentido histórico, sino en la carne misma de las indias. El símbolo de la entrega es doña Malinche, la amante de Cortés. Es verdad que ella se da voluntariamente al Conquistador, pero éste, apenas deja de serle útil, la olvida. Doña Marina se ha convertido en una figura que representa a las indias, fascinadas, 
Cuauhtémoc, o último tatloani asteca que liderou a luta contra os invasores, é um herói mexicano. Malinche, sua antagônica, o outro lado da representação, é a que foi seduzida, violada:

Cuauhtémoc significa "águia que cai". O chefe mexicano sobe ao poder quando começa o cerco do México-Tenochtitlan, quando os astecas foram sendo sucessivamente abandonados por seus deuses, vassalos e aliados. Sobe apenas para cair, como um herói mítico. (Paz, 1947, 34). ${ }^{8}$

Dela, como já se disse, veio o xingamento, a palavra que tem a intenção de ofender: malinchista.

Daí o sucesso do adjetivo depreciativo "malinchista", recentemente colocado em circulação pelos jornais para denunciar todos os infectados por tendências estrangeiras. Os malinchistas são os partidários de que o México se abra ao exterior: os verdadeiros filhos de Malinche, que são os Chingados em pessoa. Mais uma vez, o fechado aparece em oposição ao aberto. Nosso grito é uma expressáo da vontade mexicana de vivermos fechados ao exterior, sim, mas acima de tudo, fechados em relação ao passado. Nesse grito, condenamos nossa origem e negamos nosso hibridismo. A estranha permanência de Cortés e da Malinche na imaginação e sensibilidade dos mexicanos atuais revela que são mais que figuras históricas: são símbolos de um conflito secreto, que ainda não resolvemos. Ao repudiar a Malinche - a Eva Mexicana, como José Clemente Orozco a representa em seu mural da Escola Nacional Preparatória - o mexicano rompe seus laços com o passado,

violadas o seducidas por los españoles. Y del mismo modo que el niño no perdona a su madre que lo abandone para ir en busca de su padre, el pueblo mexicano no perdona su traición a la Malinche. Ella encarna lo abierto, lo chingado, frente a nuestros indios, estoicos, impasibles y cerrados. Cuauhtémoc y dońa Marina son así dos símbolos antagónicos y complementarios. (Paz, 1947, 35).

8 Cuauhtémoc quiere decir "águila que cae". El jefe mexica asciende al poder al iniciarse el sitio de México-Tenochtitlán, cuando los aztecas han sido abandonados sucesivamente por sus dioses, sus vasallos y sus aliados. Asciende sólo para caer, como un héroe mítico. (Paz, 1947, 34). 
nega sua origem e entra só na vida histórica. $\mathrm{O}$ mexicano condena em bloco toda a sua tradição, que é um conjunto de gestos, atitudes e tendências em que já é difícil distinguir o que é espanhol do que é indígena. Por isso a tese hispanista que nos faz descender de Cortés excluindo a Malinche é a herança de algumas pessoas extravagantes, que nem sequer são brancos puros. (Paz, 1947, 35). ${ }^{9}$

\section{Essa visão mais nacionalista começava a se formar na segunda metade do} século XX, mais exatamente de 1940 a 1970; não a de que Malinche fosse uma vítima, mas sim uma traidora da pátria: aquela que tinha escolhido por sua livre e espontânea vontade formar uma aliança com o invasor; por isso, seu nome passa a ser associado com o epíteto malinchista. ${ }^{10}$

\section{Nos anos 70, por uma visão satírica de vários autores mexicanos, Malin- che se tornaria defensora dos povos nativos e mais poderosa que Hernán}

9 De ahí el éxito del adjetivo despectivo "malinchista", recientemente puesto en circulación por los periódicos para denunciar a todos los contagiados por tendencias extranjerizantes. Los malinchistas son los partidarios de que México se abra al exterior: los verdaderos hijos de la Malinche, que es la Chingada en persona. De nuevo aparece lo cerrado por oposición a lo abierto. Nuestro grito es una expresión de la voluntad mexicana de vivir cerrados al exterior, sí, pero sobre todo, cerrados frente al pasado. En ese grito condenamos nuestro origen y renegamos de nuestro hibridismo. La extraña permanencia de Cortés y de la Malinche en la imaginación y en la sensibilidad de los mexicanos actuales revela que son algo más que figuras históricas: son símbolos de un conflicto secreto, que aún no hemos resuelto. Al repudiar a la Malinche-Eva mexicana, se-gún la representa José Clemente Orozco en su mural de la Escuela Nacional Preparatoria- el mexicano rompe sus ligas con el pasado, reniega de su origen y se adentra solo en la vida histórica. El mexicano condena en bloque toda su tradición, que es un conjunto de gestos, actitudes y tendencias en el que ya es difícil distinguir lo español de lo indio. Por eso la tesis hispanista, que nos hace descender de Cortés con exclusión de la Malinche, es el patrimonio de unos cuantos extravagantes, que ni siquiera son blancos puros. (Paz, 1947, 35).

10 Palma $(1990,138)$ afirma que o termo se configurou no México para culpar todas as mulheres representadas por Malinche, pela tragédia que significa a existência do homem mestiço mexicano e que teria começado, simbolicamente, com o nascimento de Martín, o primeiro mestiço, filho de espanhol Hernán Cortés com essa indígena. 
Cortés, o que entrava em discordância com o olhar de José Limón apenas no ponto em que o diretor musical não tinha esse olhar irônico sobre esse poder da indígena. $\mathrm{O}$ uso do termo malinchista passou a ser usado, de forma preconceituosa, dos anos 30 até a década de 70, para estigmatizar não somente indígenas mexicanas, mas também mexicanas-americanas. Esse uso sexista chamou a atenção de acadêmicas feministas para a figura de Malinche.

\section{LA MALINCHE EM ESPETÁCULO MUSICAL}

Na representação de José Limón de La Malinche, o autor incorporou temas da arte mexicana e da história, se inspirando na arte mexicana para confeccionar seus painéis de paisagem e figurino; sua escolha também reflete as históricas tradiçóes artísticas da Espanha, da América indígena e o grande renascimento do mural mexicano do século XX. Sua preferência por temas do passado reflete a maneira única em que as memórias históricas da Conquista aconteceu primeiramente nos Estados Unidos, depois no México, Rússia, Canadá, Europa e permaneceu por décadas como a mais popular apresentaçáo no exterior.

A figura de Malinche, personagem feminina central no imaginário cultural mexicano contemporâneo, justifica o sucesso do musical. Montandon $(2007,137)$ sublinha que de forma geral, a não ser para Limón, passa despercebido o resgate que os mexicanos - mesmo numa nação essenciamente patriarcalista - fizeram ao aproximar simbolicamente as figuras de 
"la Llorona" ${ }^{11}$ de la Malinche e, paradoxalmente, da Virgem de Guadalupe. Vejamos suas observaçôes:

E a esse respeito chamamos a atenção para as palavras do antropólogo chicano Jose Limón, que atenta para a pequena ou nula atenção que a historiografia mexicana tem dado ao fato de que a sociedade mexicana, táo fortemente machista e patriarcal, desde cedo tenha articulado sua história antiga e sua nacionalidade justamente em torno dos símbolos femininos. Malinche continua a ser um ícone cultural feminino compartilhado pela cultura mexicana e mexicano-americana, o que justifica o protagonismo dela no espetáculo musical de José Limón. (Montandon, 2007, 137)

Ainda que Seed (2008) realize um mapeamento das percepçóes que diversos acadêmicos fizeram da Malinche através dos anos, clarifica que sua própria visão é de que ela usava seus talentos alternadamente tanto para o lado espanhol quanto para o mundo indígena, numa busca que jamais encontra um momento final de hibridismo.

Segundo a própria Seed $(2008,9)$, em 1949, Limón criou seu musical observe-se que somente dois anos após o ensaio de Paz. Entretanto, o fez com outra visão sobre a Malinche, mais adequada à interpretação do Lienzo de Tlaxcala $^{12}$, isto é, retratando-a como protagonista da conquista do México

11 De acordo como Gordon $(2005,4)$, “la Llorona” da tradição indígena mexicana é uma figura que chora por seus filhos perdidos. Nesse sentido, a Malinche estaria no lugar de todas as mulheres indígenas que lamentam terem tido filhos com espanhóis.

12 Segundo Seger $(2014,12)$, "Lienzo de Tlaxcala" é um documento que pretendia mostrar ao rei da Espanha, Carlos V, toda a ajuda dada pelos tlaxcaltecas aos espanhóis nos episódios da conquista. Sua produção data do século XVI e foi feita a partir da memória dos acontecimentos ocorridos entre 1519 e 1521, quando Cortés deu início à sua aventura na América. Ele foi confeccionado em estilo pictográfico, composto por cerca de noventa e uma imagens, em vinte e duas das quais Malinche se encontra representada. 
que a faz permanecer no palco durante todo o espetáculo. $\mathrm{O}$ espetáculo musical se compóe de apenas três personagens: o Conquistador, sempre acompanhado de Malinche e carregando uma cruz em forma de espada, derrota o terceiro personagem, um indígena que, ao se perceber derrotado, culpa e critica o desempenho de Malinche que chora e se arrepende.

Quando exibido no México, o espetáculo obteve elogios de alguns, mas não em relação à visão de Limón sobre Malinche, táo contrária à opiniáo local que convergia com a interpretação de Octávio Paz. Na representação de Limón, Malinche não é vítima daquele que chegou para derrotar o indígena mexicano e sim sua comparsa, aquela que, em seu livre-arbítrio, se junta a ele nessa conquista, sendo que nenhum indício de traição transtorna essa associaçáo. Seed (2008) descreve a cena final do musical como uma solução política significativa com a identidade do indivíduo renovada através de um renascimento, pois o indígena desaparece sob as saias da Malinche apenas para renascer. A ambiguidade do mestiço, diz a autora, sugere uma resoluçáo mais equívoca para o conflito entre espanhóis e indígenas, insinuando o potencial ressurgimento de uma cultura indígena, não totalmente derrotada após a conquista. $\mathrm{O}$ segundo motivo do sucesso do espetáculo deriva do apelo contínuo ao assunto e ao papel continuado de Malinche como um ícone cultural controverso que provoca as mais diversas interpretaçóes tanto na literatura, como nas lutas políticas do México e Estados Unidos.

A Malinche foi, também, reconstruída como um símbolo de independência sexual e Limón previu essa visão de Malinche como força e poder das mulheres indígenas que, além do mais, conforme registros históricos, já 
eram consideradas poderosas dentro dos povos indígenas; de fato, as mulheres astecas se inscreviam como autoridades reais em suas comunidades. Limón coreografou seu espetáculo há 50 anos e o tema em torno a essa personagem complexa e contraditória continua a fascinar e atrair muitos, até mesmo de fora dos círculos literários e intelectuais e, inclusive, de fora do México e dos Estados Unidos.

Shelley C. Berg (2008), em seu artigo intitulado "La Malinche: The Inspiration for the Dance" - que compóe o livro José Limón and La Malinche editado por Patricia Seed - diz que em La Malinche, Limón refinou ainda mais a técnica de comprimir seus princípios políticos em um único personagem: a Malinche. A autora $(2008,25)$ resume o espetáculo: quando o ballet começa, Malinche, Cortés e o personagem que representa o indígena entram no palco com outros viajantes, até que cada um deles realiza um breve solo de introdução. A seguir, Malinche e o conquistador Cortés performam um dueto no qual transmitem a concepção de Limón sobre o que a Conquista representa para ele; logo após, é representada a capitulação dos astecas. Nesse momento, uma Malinche muito feminina oferece uma flor que funciona como um emblema do México e como uma referência à guerra das flores. Nessas guerras os astecas guerreavam contra um povo vizinho previamente escolhido e avisado, e quando a luta se dava, os guerreiros vencidos serviam de escravos ao povo vencedor e de sacrifício para os deuses. Vale ressaltar que os astecas não iam para batalhas sem uma grande formalidade que as antecedesse. A guerra, para eles, respondia a diferentes conceitos; não era somente para matar, pois costumavam fazer guerras cerimoniais para 
mostrar força e capacidade de dominar e de, quando se fizesse necessário, fazer escravos e vítimas para os sacrifícios. Todorov (2003) também nos fala que esse foi um dos fatores que teve relevância na guerra imposta aos astecas pelos espanhóis:

Os astecas não concebem e não compreendem a guerra total de assimilação
que os espanhóis estão fazendo contra eles (inovando em relação à sua
própria tradição); para eles, a guerra deve acabar num tratado, estabelecendo
o montante dos tributos que o perdedor deverá pagar ao vencedor. Antes
de ganhar a partida, os espanhóis já tinham obtido uma vitória decisiva: a
que consiste em impor seu próprio tipo de guerra; a superioridade deles já
não é mais posta em dúvida. (Todorov, 2003, 54-55)

Os astecas não guerreavam sem um minucioso cerimonial onde tudo era previsto de antemáo. Os guerreiros marcavam o lugar e todos os povos dali deixavam um espaço sem nenhum tipo de plantação, longe das povoaçóes, para que ali se dessem as batalhas. Esse cerimonial estabelecia as regras: até mesmo o tempo que as batalhas durariam era pré-definido e, antes de seu início, soltava-se uma saraivada de flechas.

No final do espetáculo musical, surge um Hernán Cortés muito frio e resoluto que segura diante de si uma espada em forma de cruz, aceita a flor e coloca a espada sobre os ombros da Malinche que está de braços abertos, também em forma de cruz, representando a vitória da religiáo católica sobre a fé e iconografia asteca.

Berg $(2008,25)$ entende que o fruto da união desses dois personagens será mestiço, e que o destino dos mexicanos se liga à associação de ambos, ou seja, o destino histórico dessa prole será carregar essa cruz. De fato, essa 
prole provém da Malinche: indígena que, primeiramente, se subordina ao conquistador, depois passa a ser sua amante e, logo após, em cumplicidade e por açấo voluntária, racional e premeditada, póe-se - em eventos importantes para a conquista - ao lado dele. Aliás, ao converter-se ao catolicismo, abandona os deuses de sua terra para abraçar a cruz do estrangeiro. No próprio texto de Berg $(2008,26)$ comenta-se a analogia entre cidade e mulher presente na descrição de Cortés: quando ele entra em Tenochtitlán e a descreve como maravilhosa e de inacreditável beleza, tanta como qualquer homem ao elogiar as maravilhas de uma mulher, com o êxtase da primeira vez. Assim, no espetáculo, Cortés realiza uma posse sexual, pessoal e política.

A descrição do espetáculo realizada por Berg continua: a Malinche está atrás de Cortés, longe dele e num nível inferior, mas ele se aproxima, desloca a espada para máo esquerda, levanta a mulher e a coloca de frente para ele. A Malinche arqueia-se novamente, ele a segura em seus braços, a abraça e a embala. Este movimento é seguido por um poderoso momento simbólico no qual ela enfrenta seu conquistador, segura a espada e mergulha-a na terra, entre eles. Aqui, Berg $(2008$, 26) vê uma associação entre a Malinche de Paz e a de Limón: o conquistador seria o macho agressivo que perpetra a violência na qual a Malinche, representando seus filhos, seria símbolo dessa agressão praticada; pela espada e pela cruz de Cortés é simbolizada a violência do homem que entrou na terra alheia esmagando os ídolos, arrasando os altares e exigindo sua substituição absoluta pela fé católica, uma fé absolutamente estranha e indesejada por aqueles que lá estavam. 
O personagem que representa Cortés dança imponentemente e Malinche assume a mesma postura; se adequa mimeticamente à imagem do conquistador. Logo, com sua espada, ele traça um círculo em torno de si e nele inclui a mulher, um dos espólios de sua vitória. Dentro do círculo está o indígena que aponta um dedo acusador para Malinche, quem, meio arqueada pelo peso da culpa chora. O espetáculo se encerra, como já antecipamos baseados no estudo de Seed $(2008,29)$, com Malinche cobrindo o indígena com sua saia: logo após, o expulsa dali e, imediatamente o abraça, configurando uma reminiscência à La Pietá. Ele, então, que representa o México, a empurra; repudia Malinche que se encontra curvada pelo peso da tristeza. No entanto, seu espírito se eleva, e ela transmite sua força ao indígena, revigorando-o. Ele, fortalecido, revela-se já um sem-terra, revolucionário, que pretende derrotar Cortés e recuperar seu país.

A autora salienta a passagem, fortalecida pela coreografia que traz muitas imagens de Quetzalcóatl, o Serpente Emplumada, que simbolicamente faz uma aproximação do indígena ao bondoso deus asteca que é contra os sacrifícios de sangue. De subserviente, o indígena transforma-se naquele que faz guerra contra o estrangeiro que veio para destruir seu mundo. Ele, por três vezes, enfrenta o conquistador e a Malinche, perdoada pelo indígena, se junta a ele nas batalhas contra o invasor.

Carol Maturo, no artigo "Visual Communication Props and Costumes" publicado no livro organizado por Seed, salienta $(2008,55)$ que quando Limón criou o espetáculo La Malinche, ele já estava morando fora do México por 34 anos e somente tinha ouvido falar sobre essa figura através de lendas 
folclóricas contadas por seus pais e avós; porém, nelas, Limón não teria encontrado inspiração para projetar os trajes, os conceitos e as visóes que traduzissem completamente o que ele queria transmitir com o espetáculo. Além disso, Maturo $(2008,55-56)$ também assinala que o autor pode ter se baseado em trabalhos de artistas que foram afetados pelo nacionalismo cultural que marcou as comunidades artísticas do início do século XX. Esse nacionalismo fez com que se encontrasse inspiração para esses trabalhos na herança indígena e em uma reavaliação do papel desse na história e na sociedade mexicana, similarmente ao que aconteceu no Brasil, considerando a invisibilidade dos indígenas enquanto sujeitos históricos no século XIX.13 Entre os artistas afetados por esse nacionalismo cultural se encontram Frida Kahlo, Rufino Tamayo, David Alfaro Siqueiros, Diego Rivera e José Clemente Orozco. Todos eles partiram do princípio de que o México era uma terra de mestiços, descendentes de espanhóis e indígenas. Para Maturo (2008, 75), Orozco e Rivera retratavam figuras do passado do México com diferentes visóes sobre o assunto; enquanto os murais de Rivera narravam um processo literalmente histórico, com personagens como Montezuma, Malinche e Cortés, descritas durante a guerra da conquista de 1519, os murais de Orozco representavam, simbolicamente, o deus das lendas mexicanas, Quetzalcóatl, que prometera regressar um dia para sua terra natal.

13 No palco da história, os índios vão, lentamente, passando da invisibilidade construída no século XIX para o protagonismo conquistado e restituído nos séculos XX e XXI por movimentos políticos e intelectuais nos quais eles próprios têm tido intensa participação. Desde a década de 1990, os historiadores no Brasil têm se voltado para o estudo dos índios, valorizando-os como sujeitos dos processos históricos por eles vivenciados. (Almeida, 2012, 21). 
"Jose Limon and La Malinche in Mexico: A Chicano Artist Returns Home", artigo que consta no livro organizado por Seed, foi escrito por Tortajada Quiroz (2008) com o objetivo de inventariar a dança etnicamente inspirada. Nesse sentido (2008, 119), aponta que, em 1947, surgiu a Academia de Dança Mexicana e um ano depois foi fundado o Balé Nacional do México. Diz-nos a autora que, em 1946, Miguel Alemán Valdés assume a presidência do México como o primeiro governante civil pós-revolucionário para continuar a política da Revolução Mexicana, com um discurso político nacionalista que fortaleceu o surgimento dos murais nacionalistas de Rivera e Orozco. Em 1950, Limón é convidado para levar ao México seus espetáculos de dança moderna e causa um grande impacto, por ser um mexicano que teria sabido trazer para a dança o poder de sua ancestralidade, dando a ela um sabor mexicano. Limón, certamente, inspirou-se no trabalho desses dois artistas, mas também no Lienzo de Tlaxcala, no Código Florentino de Bernardino de Sahagún, entre outros documentos históricos, pois três dos adereços de La Malinche - a flor, a espada e a roupa da Malinche - mantêm impressionantes semelhanças visuais com o Lienzo.

No artigo "Marina, Malinche, Malintzin Nahúa Women and the Spanish Conquest", também presente no livro organizado por Seed, Susan Kellogg (2008) reflete sobre a vida das mulheres astecas e, por consequência, sobre a vida da Malinche antes da chegada dos espanhóis. Assim aborda sua provável passagem de nobre e filha de caciques à escrava e, posteriormente, sua "coisificação", quando se torna objeto a ser doado em troca de alianças políticas. Paradoxalmente, observa a autora, as mulheres indígenas eram 
independentes e autônomas, podiam ocupar papéis de autoridade. Nesse sentido, Kellogg $(2008,81)$ pretende mostrar como Malinche ilustra aspectos importantes da vida das mulheres e seus papéis na pós-conquista. A autora parte do princípio de que a relação de Cortés e a Malinche sintetiza o caráter das relaçóes entre nativas e espanhóis, pois ele foi pai de quatro filhos com a segunda esposa, espanhola, casamento que ocorreu após seu relacionamento com a Malinche, sendo que com a primeira esposa, também espanhola, não tivera filhos. $\mathrm{O}$ conquistador ganhou, ainda, outro filho fora do casamento, também com uma mulher espanhola - no caso, uma prima - e outros quatro filhos mestiços, com quatro diferentes mulheres indígenas, uma das quais foi Malinche. Muitas vezes, geravam-se crianças entre espanhóis e indígenas que foram legitimadas pelos pais, como no caso de Cortés, que reconheceu o filho que teve com Malinche e o enviou para a Espanha, ainda menino, para ser educado. Esse filho foi batizado com o nome de Martin, em homenagem ao pai de Hernán Cortés.

As relaçóes entre homens espanhóis e mulheres indígenas foram violentas, muitas vezes de estupro, até mesmo coletivo. Kellogg $(2008,90)$ diz, corroborada por diversos historiadores, que houve - na conquista e colonização - tantas violaçóes sexuais contra as mulheres por parte dos espanhóis que chegaram a ser vistas como uma parte normal dessa gama de relaçóes. A frequência de violência sexual e a pré-disposição de Cortés em distribuir as mulheres indígenas entre seus homens mostra que esses conquistadores usavam o falo como extensão de suas espadas e que a violência, a violaçáo e o abuso foram atributos dos atos dos espanhóis tanto contra a cultura 
dos indígenas, quanto aos seus deuses, suas terras e suas mulheres. Nesse sentido, quem pode dizer que este não seja um aspecto a considerar no relacionamento de Malinche com os estrangeiros?

Em "Malinche in Cross-Border Historical Memory", outro dos capítulos do livro organizado por Seed, Sonia Hernández $(2008,99)$ pontua questóes sobe racismo e sentimentos anti-indígenas e lembra que a Malinche evoca questóes de orgulho e raça, sendo que muitos não gostam da ideia de ser descendentes dela. Inclusive, acrescenta, alguns mexicanos conseguem justificar suas personalidades explosivas pelo fato de terem herança indígena e pela mistura de sangue indígena e espanhol. A vida e a herança que a Malinche deixou mostram uma relação íntima entre índole e mestiçagem.

Segundo a autora $(2008,95)$, o epíteto malinchista não se refere diretamente ao nome da Malinche, mas à percepção política da traição a seu povo. Esta concepção surgiu na Revolução Mexicana, durante o governo de Porfirio Díaz, em uma ditadura cujos líderes eram contrários aos privilégios concedidos a estrangeiros e reescreveram a história do México: assim, os espanhóis seriam os intrusos e quem os tivesse ajudado, seriam os traidores da nação. A partir de então, Malinche passou a ser considerada uma traidora: aquela que traiu seu próprio povo em benefício dos invasores estrangeiros e, mesmo depois dessa situação política ter sido ultrapassada, o nome de Malinche continuou a ser sinônimo de traição. Segundo Hernández (2008, 107), no sul do Texas, o epíteto identifica, por exemplo, uma mulher que se casou com um norte-americano; enfim, fazemos a observação para registrar 
que malinchismo é um termo que ultrapassou fronteiras. Dentro do México, alguns ignoram essa personagem e sua relação com a mestiçagem, mesmo porque muitos espanhóis tiveram filhos com indígenas. Malinche e seu filho Martin não foram os primeiros, mas somente se tornaram os mais importantes símbolos de mestiçagem. Para esses mexicanos, ela era simplesmente uma indígena que sabia as línguas necessárias para ser a tradutora e o fato de ter tido um filho com Cortés não significa que desempenhou um papel na criação de uma nova raça. Julgam, ainda, que teve suas próprias razóes para agir como agiu. Para alguns, inclusive, Cortés se apossou do que quis dentro do México, não só da Malinche, mas de tudo e de todos. Outras opiniôes são de que havia uma natureza coercitiva no relacionamento, que o que importava realmente era a vontade de Hernán Cortés e não a da Malinche. O certo é que há uma luta entre o passado que inclui a Malinche, pelo lado dos indígenas e que inclui Cortés, pelo lado dos espanhóis. Os espanhóis são defendidos por aqueles que julgam que esses trouxeram a fé católica e um "verdadeiro Deus". Até mesmo Limón, como registra Seed (2008, 102), afirmou: "Afinal, a Espanha também é a pátria mãe; ela nos deu nosso senhor Jesus Cristo e sua crucificaçấo".

\section{ChICANAS E O FeMinismo}

Quando Octávio Paz retratou a Malinche como a mulher que representava a traição à pátria - como aquela que se entregou a um estrangeiro - motivou uma revolução entre as feministas. Enquanto Malinche era a índia seduzida, 
Cuauhtémoc representava o herói que resistiu à invasão dos estrangeiros. Ele, o homem, era o bem; ela, a mulher, representava a violação, a traição, o mal.

O retrato do macho dominante de Paz sobre a história da criação do México proporcionou uma motivação convincente para que as acadêmicas do final do século XX reavaliassem suas definiçóes de gênero. É importante fazer uma pausa e reconhecer interpretaçôes feministas consistentes que ocasionalmente interrompiam o modo de pensamento patriarcal ilustrado por Paz. O México tem uma longa história de mulheres contribuindo para o diálogo nacional, começando com Sor Juana Inez da Cruz. (Jager, 2015, 201, tradução nossa)..$^{14}$

Jager $(2015,161)$ acrescenta que as estudiosas feministas dos anos 70 viram a Malinche como uma escrava indígena abusada pelos espanhóis, assim como pelos homens indígenas a quem servia sexualmente. Da sua parte, as feministas chicanas representavam a Malinche como uma mulher que lutava contra o patriarcalismo ainda que esta instituição não fosse legitimada na Espanha durante a vida da indígena tradutora de Hernán Cortés. Cada grupo de feministas usava e projetava a figura de Malinche de acordo com suas próprias ideologias de gênero. As chicanas muitas vezes ignoravam que as mulheres indígenas dispunham da mesma influência, prestígio e poder que os homens indígenas na sociedade em que estavam imersas. A esse respeito Jager observa:

14 Paz's male-dominant portrayal of Mexico's creation story provided compelling motivation for latetwentieth-century female scholars to reevaluate his gender definitions. It is important to pause and acknowledge consistent feminist interpretations that occasionally interrupted the patriarchal mode of thinking illustrated by Paz. Mexico has a long history of women contributing to the national dialogue, beginning with Sister Juana Inez de la Cruz. (Jager, 2015, 201). 
Nas décadas seguintes ao movimento dos direitos civis, a política étnica dominou os Estados Unidos em uma discussão nacional sobre diversidade e justiça social. As mexicanas-americanas participaram desta discussão, exigindo igualdade e tolerância por meio do movimento chicano. As chicanas fundamentaram sua identidade cultural do século XX reivindicando descendência dos ancestrais astecas que se originaram da mítica cidade de Aztlan. Eles acreditavam que a pátria ancestral existia em algum lugar no sudoeste dos Estados Unidos. Ao estabelecer uma pré-história nos Estados Unidos fortaleceram suas demandas por igual cidadania. Eles não eram estranhos; eles eram descendentes de nativos americanos antigos que haviam migrado para o México nos anos 1200. (Jager, 2015, 203, tradução nossa). ${ }^{15}$

As discussões sobre orientação sexual tornaram-se um dos mais importantes eixos de debates entre as intelectuais que se opunham à opressão feminina. Os homens chicanos que lutavam somente por igualdade racial não aceitaram que debates de gênero fossem incorporados à causa. Jager (2015, 11) diz que eles passaram a chamá-las de traidoras e excomungá-las do movimento. Segundo Seger (2014), essas chicanas foram perseguidas por serem influenciadas por feministas norte-americanas, por se abrirem à doutrina estrangeira, tal como interpretavam que tinha acontecido com a Malinche.

Enquanto chicanos tendiam a difamar Malinche, as feministas chicanas a celebravam. Para eles, ela era o exemplo definitivo de uma mulher forte que podia sair dos limites das normas sociais - ainda que normas sociais do

15 In the decades following the civil rights movement, the politics of ethnicity gripped the United States in a national discussion on diversity and social justice. Mexican Americans took part in this discussion by making demands for equality and tolerance through the Chicano Movement. Chicanos grounded their twentieth-century cultural identity by claiming descent from Aztec ancestors who originated from the mythical city of Aztlan. They believed the ancestral homeland existed somewhere in the southwestern United States. Establishing a prehistory within the United States strengthened their demands for equal citizenship. They were not outsiders; they were descendants of ancient Native Americans who had migrated to Mexico in the 1200s. (Jager, 2015, 203). 
século XX - para se tornar uma força poderosa na formação da História. (Jager, 2015, 205). ${ }^{16}$

Sob a visão da crítica feminista, Malinche retorna sob um fundo revisionista, mostra-se uma figura livre, que quebra padróes hierárquicos e patriarcalistas. Sob a visão de Limón, Malinche encontra uma chance de voltar, depois da morte, para se mostrar arrependida e disposta a ajudar os indígenas, seus iguais.

\section{Conclusão}

Essa figura controversa não será indicadora de consenso entre historiadores e literatos. A Malinche é uma personagem que desperta muitas opinióes controversas e que se adapta à discussão de problemas que se referem ao feminismo, ao nacionalismo, às representaçóes de sentimentos mexicanos e chicanos. Muitos, incluindo as chicanas, tentam desconstruir os estereótipos, os rótulos e os preconceitos contra Malinche. La Malinche de Limón é um espetáculo de forte orgulho primitivo, no qual a protagonista trai seu povo, e ao morrer, dá sua alma para reparar o mal praticado. Nesse sentido, o autor vem representar uma Malinche que, ao ser trazida de volta, após a morte, surge sob um novo olhar, durante a revolução mexicana; é um espírito que voltou para se purificar de sua

16 While Chicanos tended to vilify Malinche, Chicana feminists celebrated her. For them she was the ultimate example of a strong woman who could step outside the confines of societal norms - albeit twentieth-century societal norms - to become a powerful force in shaping history. (Jager, 2015, 205). 
felonia. Entretanto, é improvável uma conclusão única sobre uma representação de Malinche.

\section{REFERÊNCIAS BIBLIOGRÁFICAS}

Almeida, Maria Regina Celestino de. "Os índios na História do Brasil no século XIX: da invisibilidade ao protagonismo”. In: Revista História Hoje, v. 1, no 2, 21-39- 2012.

Berg, Shelley C. "La Malinche The Inspiration for the Dance". In: José Limón and La Malinche: The dancer and the Dance. United States of America: University of Texas press, 2008, 20-34.

Gordon, Helen Heightsman. Malinalli of the Fifth Sun: The Slave Girl Who Changed the Fate of Mexico and Spain. Bloomington: iUniverse books, 2005.

Hernández, Sonia. "Malinche in Cross-Border Historical Memory". In: José Limón and La Malinche: The dancer and the Dance. United States of America: University of Texas press, 2008, 95-118.

Höller, Michaela. I am what I am, take it or leave me alone translating chicananess with the ayuda of la Malinche. Dissertação de mestrado. USA: Stanford University, 2010.

Jager, Rebecca Kay. Malinche, Pocahontas, and Sacagawea: Indian Women as Cultural Intermediaries and National Symbols. Oklahoma: University of Oklahoma Press, 2015.

Kellogg, Susan. Marina. "Malinche, Malintzin Nahúa Women and the Spanish Conquest". In: José Limón and La Malinche: The dancer and the Dance. United States of America: University of Texas press, 2008, 79-94.

Maturo, Carol. "Visual communication Props and Costumes". In: José Limón and La Malinche: The dancer and the Dance. United States of America: University of Texas press, 2008, 55-78. 
Montandon, Rosa Maria Spinoso de. La Llorona. Mito e poder no México. Niterói, 2007. Disponível no link: https://www.historia.uff.br/stricto/teses/Tese-2007_ MONTANDON_Rosa_Maria_Spinoso-S.pdf

Palma, Milagros. Malinche, el malinchismo o el lado femenino de la sociedad mestiza. Quito: ABYA-YALA, 1990, 131-164.

Paz, Octavio. "Los hijos de la Malinche.". In: El laberinto de la Soledad. Mexico City: Cuadernos Americanos, 1947.

Seed, Patrícia. José Limón and La Malinche: The dancer and the Dance. United States of America: University of Texas Press, 2008.

Seger, Magda Fabiane. "La Malinche, D. Marina: a 'lengua' de Cortés segundo o 'Lienzo de Tlaxcala' São Leopoldo", 2014. Disponível no link: http://www. repositorio.jesuita.org.br/handle/UNISINOS/4253.

Todorov, Tzvetan. A conquista da América: a questão do outro. Tradução de Beatriz Perrone-Moisés. 3. ed. São Paulo: Martins Fontes, 2003.

Tortajada Quiroz, Margarita. "Jose Limon and La Malinche in Mexico: A Chicano Artist Returns Home". In: José Limón and La Malinche: The dancer and the Dance. United States of America: University of Texas press, 2008, 119-153. 
